\title{
THE APPLICATION OF HYDROTROPES AS MEDIUM IN THE EXTRACTION OF ANDROGRAPHOLIDE
}

\begin{abstract}
Indah Hartati ${ }^{1}$, Laeli Kurniasari ${ }^{1}$, Yance Anas ${ }^{2}$, Nur Aniq $^{1}$
1Department of Chemical Engineering, Faculty of Engineering, Wahid Hasyim University, No. 22 Menoreh Tengah Road X, SemarangIndonesia

2Department of Pharmacy, Faculty of Pharmacy, Wahid Hasyim University No. 22 Menoreh Tengah Road X, SemarangIndonesiaa

Submitted: 09-05-2014

Revised: 13-07-2014

Accepted: $22-09-2014$

*Corresponding author Indah Hartati

Email :

ABSTRACT

Hydrotrope solutions provide safe and effective media for the microwave assisted extraction of andrographolide, the major bioactive chemical constituent of plant Andrographis paniculata. Microwave assisted extraction of androgpaholide was carried out by using hydrotropes, sodium benzoate and urea. The objective of this work were to determine the Minimum Hydrotrope Concentration (MHC) and to determine the effectiveness of each hydrotrope with respect to andrographolide at different system powers. The microwave assisted extractions of andrographolide were carried out at different concentration of hydrotropes $(0.2-3 \mathrm{M})$ and different system powers (39.9 and 119.7 Watt). Twenty grams of Andrographis paniculata dried powder were added to $200 \mathrm{ml}$ of hydrotrope solutions and extracted in a microwave extractor for 15 minutes. The research result showed that the percentage of the microwave assisted extraction of andrographolide by using sodium benzoate and urea were up to $10.9 \%$ and $1.05 \%$ respectively. The Minimum Hydrotrope Concentration and the effectiveness of hydrotropes that was measured in term of Setschenow constant $\left(K_{s}\right)$ were reported for two hydrotropes used in this study.
\end{abstract}

hartatiprasetyo@gmail.com

Key words: andrographolide, hydrotrope, microwave assisted extraction.

\section{INTRODUCTION}

Andrographolide is the primary bioactive component of the medical plant Andrographis paniculata. Andrographolide is generally extracted from leaves and aerial parts of A. Paniculata. It is reported has a broad category of pharmacological activity, such as hepatoprotective, gastroprotective, anticancer, antihyperglycemic, antimicrobial, anti-inflamatory, antioxidant, antidiarrheal and antimalarial activities (Bharati et al., 2011; Anju et al., 2012).

Conventional methods employed in the andrographolide extraction such as maceration (US Patent no 7341748) and solvent extraction (Avanigadda and Vangalapati, 2010) though were reported as an effective methods, they were also reported as the cause for the thermal degradation of heat sensitive compound (Lomlin et al., 2003), the cause of the degradation of andrographolide (Wongkittipong et al., 2004; Varma et al., 2011) and leave traces of toxic solvents in the solute (Kumoro and Hasan, 2007; Laddha et al., 2010).
The suitable alternative for andrographolide separation is the hydrotropic extraction combined with microwave heating. Hidrotropic extraction utilize hydrotropes to solubilized solute that are sparingly soluble in water under normal conditions, so it will not leave any toxic traces. Meanwhile, beneficial effects of MAE with respect to medicinal plants have been published, with significant improvements over conventional extraction methods offering much lowered extraction time, much lowered temperature, enhanced product purity, and enhanced efficiency (Das et al., 2009; Dhobi et al., 2009).

In the present study, andrographolide was solubilized in two kind of hydrotropes (urea and sodium benzoate) and extracted in a microwave extraction system. The objectives of this work were to determine the Minimum Hydrotrope Concentration (MHC) and to determine the effectiveness of each hydrotrope with respect to andrographolide at different system powers. 


\section{MATERIAL AND METHODS}

\section{Raw material and chemicals}

The aerial parts of Andrographis paniculata were collected from local plantation in Gunungpati, Semarang. Urea and sodium benzoate (Sigma-Aldrich, 99\%) were purchased from CV. Damai Sejahtera Prima.

\section{Apparatus}

Microwave assisted extraction was conducted in a modified domestic microwave. The microwave was modified and equipped with extraction flask and a spiral condensor (Figure 1).

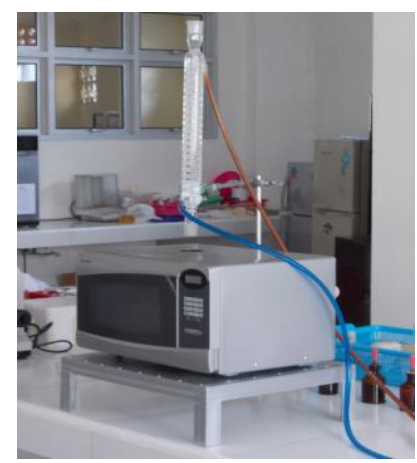

Figure 1. Modified microwave extractor

\section{Extraction}

Aerial parts of Andrographis paniculata were collected, dried and powdered. $20 \mathrm{~g}$ of dried powder was subjected in $200 \mathrm{~mL}$ of hydrotrope solution $(0.2-3 \mathrm{M})$. The mixture placed in $500 \mathrm{~mL}$ round bottom flask and extracted in a modified microwave extractor for $15 \mathrm{~min}$ at different system powers (39.9 and $119.7 \mathrm{~W})$. The mixture then was allowed to stand for $1 \mathrm{~h}$ and then filtered. The residu was washed with water and double volume of demin water was added. The extract was then centrifuges for $15 \mathrm{~min}$ at $4000 \mathrm{G}$, dried and weighed.

\section{Data analysis}

The percentage of the extraction yield $(\mathrm{w} / \mathrm{w})$ for andrographolide was obtained by using the formula:

$$
\begin{aligned}
E= & \frac{\text { mass of the extract }}{\text { mass of the sample }} \times 100 \% \\
& \text { A plot of } \log \left(E / E_{m}\right) \text { versus }\left(C_{s}-C_{m}\right)
\end{aligned}
$$
at different system power was then drawn, where $E$ and $E_{m}$ are the percentage of the extraction yield at any hydrotrope concentration $\mathrm{C}_{\mathrm{s}}$ and the minimum hydrotrope concentration $\mathrm{C}_{\mathrm{m}}$ respectively. The slope of the graph was the Setschenow constant $\left(\mathrm{K}_{\mathrm{s}}\right)$.

\section{RESULT AND DISCUSSION}

The effectiveness of each hydrotrop with respect to andrographolide obtained from microwave assisted extraction at different system powers were determined by analyzing the solubility of each case based on the Setschenow model and later modified by Phatak and Gaikar (Dhinakaran et al., 2012), as given by equation:

$\log \left(E / E_{m}\right)=k_{s}\left(C_{s}-C_{m}\right)$

A series of extraction conducted in order to obtain Setschenow constant of each hydrotropes. $20 \mathrm{~g}$ of dried powder was subjected in $200 \mathrm{~mL}$ of hydrotrope (urea and sodium benzoate) solution $(0.2-3 \mathrm{M})$. The mixture placed in $500 \mathrm{~mL}$ round bottom flask and extracted in a modified microwave extractor for $15 \mathrm{~min}$ at two system powers (39.9 and $119.7 \mathrm{~W}$ ). The mixture then was allowed to stand for $1 \mathrm{~h}$ and then filtered. The residu was washed with water and double volume of demin water was added. The extract was then centrifuges for $15 \mathrm{~min}$ at $4000 \mathrm{G}$, dried and weighed.

The experiment result showed that used of $3 \mathrm{M}$ sodium benzoate solution as medium in the microwave assisted extraction conducted at 119.7W found to give the highest mass of the extract, $2.18 \mathrm{~g}$. Meanwhile, on the same process parameter, the utilization of urea as extraction medium gave only $1.05 \mathrm{~g}$ of extract.

Based on mass data, the percentage of the extraction was then calculated, minimum hydrotrope cencentration (MHC) was then determined and a plot of extraction percentage versus hydrotrope concentration at two system powers was then drawn. Setschenow constant $\left(\mathrm{K}_{\mathrm{s}}\right)$ obtained from the slope of the graph.

The percentage of the microwave assisted extraction by usage of $3 \mathrm{M}$ sodium benzoate at power level of $119.7 \mathrm{~W}$ was found to be about $10.91 \%$ (Figure 2). Meanwhile the percentage of the microwave assisted extraction by usage of $3 \mathrm{M}$ urea at power level of $119.7 \mathrm{~W}$ was found to be about 1.05\% (Figure 3). 


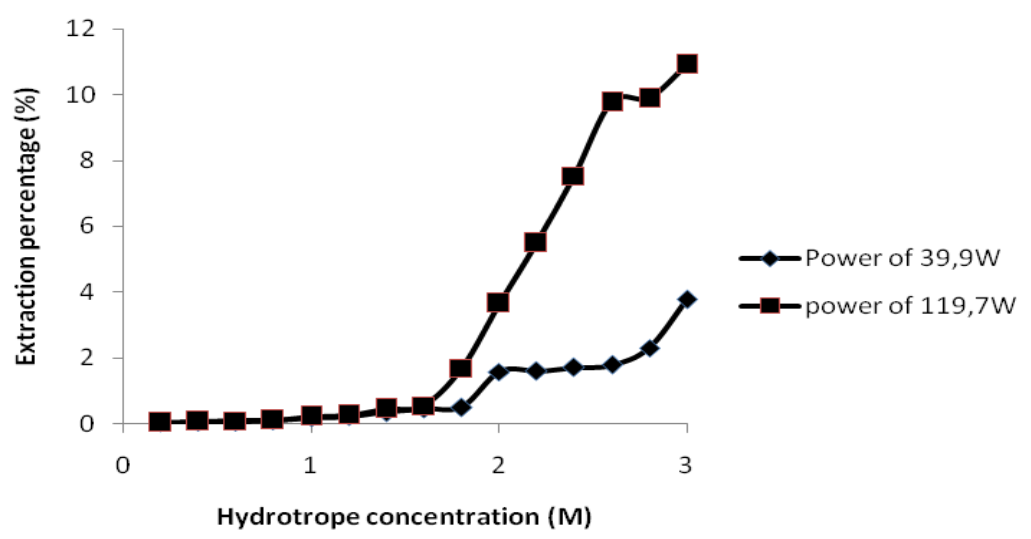

Figure 2. The effect of sodium benzoate concentration toward the percentage of andrographolide extraction.

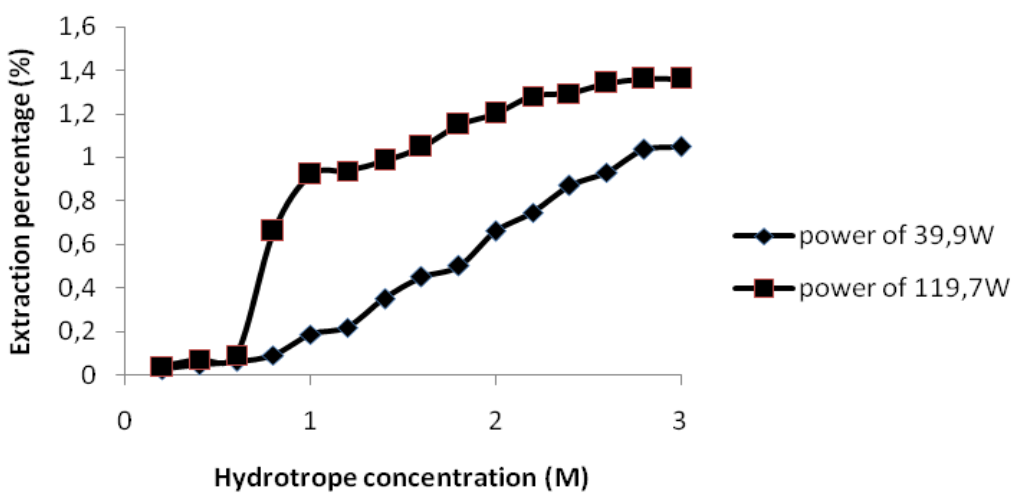

Figure 3. The effect of urea concentration toward the percentage of andrographolide extraction.

The value of the extraction percentage found in this work was higher than extraction yield of andrographolide MAE conducted by Vasu et al. (2010). The extraction yield was found to be about $0.589 \%$ at the usage of methanol as solvent in a MAE that was conducted at $210 \mathrm{~W}$ for $40 \mathrm{~min}$ (Vasu et al., 2010). Moreover, the extraction yield was found to be about $0.2 \%$ at the supercritical fluid extraction of andrograholid (Kumoro and Hasan, 2007).

Furthermore, soxhletation of $A$. Paniculata in $60 \%$ ethanol at $22^{\circ} \mathrm{C}$ for $3.5 \mathrm{~h}$ was gave extraction yield of $0.01 \%$ (Wongkittipong et al., 2004). The high extraction percentage found in the utilization of hydrotrope as MAE medium might be due to the result of hydrotropic action toward the phospolipid layer of plant cell wall and facilitate the solute dissolution (Dongre et al., 2011).

The hydrotrope is able to destroys the phospolipid bilayer of plant cell wall. Then, hydrotrope penetrates through into the inner structures. Moreover, the hydrotrope solutions break open the water impermeable suberin lamella and then the mature cork cells. The cork cell layers are disturbed by the hydrotrope and the aqueous solution penetrates through the cell wall (Dongre et al., 2011).

When the inner part is exposed to the hydrotrope solution, the cell swells, and frees the cells from closely bound structures. Hydrotropic solutions precipitated the solutes out of the solution on dilution with water thus enable the ready recovery of the dissolved solutes. 
Tabel I. MHC and Setschenow Constant of hydrotropes

\begin{tabular}{ccccc}
\hline \multirow{2}{*}{ Hydrotrope } & \multicolumn{2}{c}{ MHC $\mathbf{( M )}$} & \multicolumn{2}{c}{ Setschenow Constant } \\
\cline { 2 - 5 } & $\mathbf{3 9 . 9 W}$ & $\mathbf{1 1 9 . 7 W}$ & $\mathbf{3 9 . 9 W}$ & $\mathbf{1 1 9 . 7 W}$ \\
\hline Urea & 1 & 0.8 & 0.054 & 0.170 \\
Sodium benzoate & 1 & 1 & 0.703 & 0.978 \\
\hline
\end{tabular}

The effect of hydrotrope soaking toward the rupture of plant cell wall was also reported by Raman et al. (2002). They extracted piperine from black pepper by using substituted aromatic sulfonates such NaNBBS, $\mathrm{NaCS}, \mathrm{NaXS}, \mathrm{NaPTS}$, and a linear aliphatic sulfate such as NaBMGS. Raman et al. (2002) mentioned that on treatment with hydrotrope solution, the water molecules penetrate into the cell wall and through the transport aqua-porins, causing swelling of the membrane proteins. The hydrotrope monomers also penetrate into the cellular structure. Cell wall and cell membrane disorganization occurs, leading to the release of piperine from within the cell into the hydrotrope solution.

If the hydrotrope action on cork cell is compared to water soaking, the water soaking shows very less effect on cork cells that made of cellulose and suberin lamella.

More over, figure 2 and 3 shows that percentage of andrographolide extraction increase significantly above a certain concentration, known as Minimum Hydrotrope Concentration (MHC). MHC is the minimum required amount of hydrotrope in the aqueous phase to commence a significant increase in the solubility of solute. The knowledge of MHC values is necessary especially at industrial levels, as it ensures ready recovery of hydrotrope for reuse (Jayakumar et al., 2012).

It was observed that the MHC of sodium benzoate in the aqueous phase oes not modify even at increased system power, i.e., 39.9 and 119.7W. Meanwhile the MHC of urea in the aqueous phase decrease from $1 \mathrm{M}$ to $0.8 \mathrm{M}$ at increased system power 39.9 and $119.7 \mathrm{~W}$, respectively (Table I).

The Setschenow constant $K_{s}$ can be considered as a measure of the effectiveness of a hydrotrope at any given conditions of hydrotrope concentration and system power. The Setschenow constant values for hydrotropes namely urea and sodium benzoate for andrographolide-water system at different system powers are listed in Table I. The highest value has been observed as 0.978 in the case of sodium benzoate as hydrotrope at $119.7 \mathrm{~W}$.

\section{CONCLUSION}

Hydrotropes are proved as a save medium for microwave assisted extraction of andrographolide. Hydrotropes were also proved increase the solubility of slightly water soluble androgpraholide. The research showed that the percentage of the microwave assisted extraction by the usage of $3 \mathrm{M}$ sodium benzoate at power level of $119.7 \mathrm{~W}$ was found to be about $10.91 \%$. The highest value has been observed as 0.978 in the case of sodium benzoate as hydrotrope at $119.7 \mathrm{~W}$. Urea has a Setschenow constant lower than sodium benzoate at the same process parameter. It can be concluded that sodium benzoate is more suitable to be used in the androgpraholide microwave assisted extraction.

\section{ACKNOWLEDGEMENT}

The authors greatly acknowledge the Ministry of Research and Technology the Republic of Indonesia for its financial support through Insinas Grant 2013.

\section{REFERENCES}

Anju, D., Jugnu, G., Kavita, S., Arun, N. and Sandeep, D. 2012. A Review on medical Prospectives of Andrographis Panuculata Nees. J.Pharm. Sci. Inn... I(I):1-4

Avanigadda, S. and Vangalapati, M. 2010. Experimental and Modelling of Andrographolide Extraction From Andrographis Paniculata. Int. J. Chem, Environmental and Pharmaceutical Res. Vol $1,32-36$

Bharati, B.D., Sharma, P.K., Kumar, N., Dudhe, R. and Bansal, V. 2011. Pharmacological Activity of 
Andrographis Paniculata: A Brief Review. Pharmacologyonline. 2. 1:10

Das, S., Mukhopadhyay, A.K. and Basu, D. 2009. Prospect of Microwave Processing: An Overview. Bulletin of Material Science, 32(1):1-13.

Dhinakaran M., Morais, A.B. and Gandhi, N.N. 2012. Reflection of Hydrotropy Technique in the Segregation of 1,1/1,2Diphenylethane. Af. J. Basic and Applied Sciences 4 (2): 55-59

Dongre, P.P., Kannur, D.M., Kosambiya, V. And Desai, B.D. 2011. Significant Role Of Hydrotropes In Extraction Of Phytoconstituents- A Review. Int. J. Pharm. Sci. Res. Vol. 2(4): 730-734

Jayakumar, C., Morais, A.B., Sreenivasan, D., Jayesh, N.G. 2012. Effect Of Hydrotropes On Solubility And Mass Transfer Coefficient Of 1, 2Dichloroethane. Int. J. Chem. Eng. and App. Sci., 2(1): 6-12

Kumoro, A.C. and Hasan, M. 2007. Supercritical $\mathrm{CO}_{2}$ Extraction of Andrographolide from Andrographis paniculata: Effect of the Solvent Flow Rate, Pressure, and Temperature. China Journal of Chemical Engineering, Vol 15: $877-883$
Lomlin, L., Jirayupong, N. and Plubrukan, A. 2003. Heat Accelerated Degradation of Solid State Andrographolide. Chemical Pharmaceutical Bulletin, Vol 51, 24-26

Raman, G. and Gaikar, V.2002. Extraction of Piperine from Piper nigrum (Black Pepper) by Hydrotropic Solubilization. Ind. Eng. Chem. Res. 41. 2966-2976

US Patent no 7341748. Crude extracts from Andrographis paniculata.

US Patent no 6224877.Process for extraction of curcuminoids from curcuma species.

Varma, A., Padh, H. And Shrivastava, N. 2011. Andrographolide: A New Plant Derived Antineoplastic Entity on Horizone. Evidence based Complementary and Alternative Medicine, Vol 2011, 1-9

Vasu, S., Palaniyappan, V., Shrishaillapa. 2010. A novel microwave-assisted extraction for the isolation of andrographolide from Andrographis paniculata and its in vitro antioxidant activity. Natural Product Research Volume 24, Issue 16, 2010

Wongkittipong,R., Prat, L., Damronglerd, S. and Gourdon, C. 2004. Solid Liquid Extraction of Andrographolide From Plants-Experimental Study, Kinetics Reaction and Model", Royal Golden Jubilee Scholarship Program 